\title{
Evaluation of the activity of CYP2CI 9 in Gujrati and Marwadi subjects living in Mumbai (Bombay)
} Tanmay S Panchabhai, Shaun F Noronha, Sanish Davis, Vishal M Shinde, Nilima A Kshirsagar and Nithya J Gogtay*

\section{Address: Department of Clinical Pharmacology, Seth GS Medical College and KEM Hospital, Parel, Mumbai 400012, India}

Email: Tanmay S Panchabhai - tanmayp04@yahoo.com; Shaun F Noronha - smartshaun@yahoo.com; Sanish Davis - sanishdavis@yahoo.com; Vishal M Shinde - vishalmshinde@rediffmail.com; Nilima A Kshirsagar - dcpkem@vsnl.com; Nithya J Gogtay* - njgogtay@hotmail.com

* Corresponding author

Published: 24 October 2006

BMC Clinical Pharmacology 2006, 6:8 doi:10.1 186/1472-6904-6-8

This article is available from: http://www.biomedcentral.com/1472-6904/6/8

(C) 2006 Panchabhai et al; licensee BioMed Central Ltd.

This is an Open Access article distributed under the terms of the Creative Commons Attribution License (http://creativecommons.org/licenses/by/2.0), which permits unrestricted use, distribution, and reproduction in any medium, provided the original work is properly cited.
Received: 08 May 2006

Accepted: 24 October 2006

\begin{abstract}
Background: Inherited differences in the metabolism and disposition of drugs, and genetic polymorphisms in the targets of drug therapy (e.g., receptors), can greatly influence efficacy and toxicity of medications. Marked interethnic differences in CYP2C19 (a member of the cytochrome P-450 enzyme superfamily catalyzing phase I drug metabolism) which affects the metabolism of a number of clinically important drugs have been documented. The present study evaluated the activity of CYP2CI9 in normal, healthy Gujrati and Marwadi subjects by phenotyping (a western Indian population).

Methods: All subjects received $20 \mathrm{mg}$ of omeprazole, which was followed by blood collection at $3 \mathrm{hrs}$ to estimate the metabolic ratio of omeprazole to 5-hydroxyomeprazole. The analysis was done by HPLC.

Results: It was seen that $10.36 \%$ of this population were poor metabolizers(PM) whereas $89.63 \%$ were extensive metabolizers(EM).

Conclusion: A genotyping evaluation would better help in identifying population specific genotypes and thus help individualize drug therapy.
\end{abstract}

\section{Background}

The differences among individuals in the way they respond to medications [1] can be attributed to inherited differences in the metabolism and disposition of drugs, and genetic polymorphisms in the targets of drug therapy (e.g., receptors) [2-4] other than the conventional factors like individual's age and race, organ function, concomitant therapy, drug interactions, and concomitant illnesses [5]. CYP2C19, a member of the cytochrome P-450 enzyme superfamily(catalyzing phase I drug metabolism) [6] affects the metabolism of a number of clinically important drugs, such as proton pump inhibitors (omeprazole [7], lanzoprazole, rabeprazole), tricyclic antidepressants (imipramine, amitryptiline), phenytoin, propranolol and benzodiazepines (diazepam) [8]. Marked interethnic differences in the polymorphism frequency $[6,9]$ have led to 21 variant alleles (CYP2C19*2 to CYP2C19*8) being documented; that predict poor metabolizers (PMs); of which the most commonly encountered ones contributing to a PM phenotype were $\mathrm{CYP} 2 \mathrm{C} 19 * 2$ and $\mathrm{CYP} 2 \mathrm{C} 19 * 3$ genotypes. The prevalence of PMs has been reported to be $2-5 \%$ in Caucasians 
$[10,11], 4-8 \%$ in Africans [12] and 11-23\% in Orientals [11].

Polymorphisms can be determined by phenotyping and genotyping methodology. The phenotyping method employs the use of "Probe Drugs". These are drugs which are characteristically metabolized by a single enzyme system and hence can be used to classify individuals as extensive metabolizers (EMs) or poor metabolizers (PMs). The disadvantages in using older probe drugs like mephenytoin has prompted the use of others like omeprazole [13] and proguanil [14]. The fact that omeprazole is almost exclusively metabolized by CYP2C19 to 5-hydroxy omeprazole and to a lesser extent by CYP3A4 to omeprazole sulphone makes it a valuable probe drug for establishing the genotype-phenotype correlation for CYP2C19.

Omeprazole is used in combination regimens for the treatment of gastric as well as duodenal ulcers, gastroesophageal reflux disease and for eradication of Helicobacter pylori infection. There exist significant differences in intragastric $\mathrm{pH}$ [15] and differences in cure rates for $H$. pylori infection [16] between extensive metabolizers (EMs) and poor metabolizers (PMs) who are treated using omeprazole. Gastric acid suppression and eradication of H. pylori infection are important determinants in the management of the pathologies mentioned vide supra. It has been shown that a higher concentration of omeprazole in PMs results in greater gastric acid suppression as compared with extensive metabolizers [15]. Whereas the frequency of these polymorphisms in North [17] and South [18] Indians (who respectively belong to Aryan and Dravidian races) has been documented, the variations in CYP2C19 activity in Western Indian population has not been determined so far. The present study thus evaluated the activity of CYP2C19 in normal, healthy, Gujrati and Marwadi subjects by phenotyping using omeprazole as the probe drug.

\section{Methods}

\section{Ethics}

The study was conducted after approval from the Institutional Review Board, and in accordance with Ethical Guidelines for Biomedical Research in Human subjects of ICMR (2000) [19]. Written, informed consent was obtained from all participating subjects.

\section{Study procedure}

The study was conducted in 170 normal healthy (by history and focused clinical examination) Gujrati and Marwadi subjects residing in the state of Maharashtra, ensuring that their native places were in the states of Gujrat and Rajasthan. The sample size was calculated assuming a $12 \%$ prevalence of PMs with $95 \%$ CI at 5\% significance. The prevalence for the sample size calculation was taken as $12 \%$ based on the data of $14 \%$ and $12 \%$ prevalence in North [14] and South [15] India respectively. Subjects were admitted to the Clinical Pharmacology ward and received Omeprazole $20 \mathrm{mg}$ (Lomac- $20^{\oplus}$, batch no: G57688, Cipla Ltd, Mumbai, India) after an overnight fast. The drug was administered orally under direct supervision and the blood sample $(10 \mathrm{ml}$ of venous blood collected from an antecubital vein into 1 tube containing $100 \mu \mathrm{L}$ Heparin) was collected in accordance with the protocol 3 hours after ingestion of the drug. Alcohol, caffeine and citrus juices were avoided for at least 48 hours before the intake of omeprazole. The plasma was separated and stored at $-20^{\circ} \mathrm{C}$ pending further analysis. Omeprazole and 5-hydroxy omeprazole plasma concentrations were determined by reverse phase high performance liquid chromatography. The analytes were detected at $302 \mathrm{~nm}$ and absorbance was set at 0.005 Aufs. The sensitivity of the method and percentage extraction was 10 $\mathrm{ng} / \mathrm{ml}$ and $90.0 \%$ for both drug and metabolite. The assay was found to be linear over the concentration range from 0.1 to $10.00 \mu \mathrm{g} / \mathrm{ml}$ with all the concentrations giving precision and accuracy within $15 \%$. The phenotyping was done based on minor modifications of the method of Kobayashi et al. [20]. Statistical analysis was performed using the Graphpad Instat statistical software (Graph Pad Software Inc., San Diego, CA, USA). The KolmogorovSmirnov test was used to test normality in the metabolic ratios.

\section{Results}

Of 170 samples 6 samples could not be analyzed for various reasons and phenotyping was done for the remaining 164 samples. There were 110 males $(67.07 \%)$ and 54 females $(32.92 \%)$, the mean age of the population being $24.79 \pm 11.51($ mean $\pm S D)(95 \% C I ; 26.55,23.03)$. Of the 164 subjects, there were 122 Gujratis ( 77 males and 45 females) and 42 Marwadis (32 males and 10 females). No subject reported any adverse event to the single dose of the drug.

The frequency histogram (Figure 1) and the probit plot (figure 2) of 164 subjects confirmed a bimodal distribution of subjects with respect to their Metabolic Ratio (MR). The antimode in the Gujrati and Marwadi (Western Indian) population was calculated to be $19.54(\log M R=$ 1.291). Individuals with an $M R>19.54$ were categorized as poor metabolizers (PMs), whereas those with $\mathrm{MR}<19.54$ were categorized as extensive metabolizers (EMs). The mean MR of the population was $6.52 \pm 0.85$ $($ mean \pm SEM) $(95 \% C I ; 8.198,4.846)$.

In the study group of 164 volunteers, 147 (89.63\%) were EMs with a mean MR of $3.27 \pm 0.36$ (mean \pm SEM) and 17 $(10.36 \%)$ were PMs with a mean MR of $36.85 \pm 3.32$ (mean \pm SEM). It was further observed that the 55 


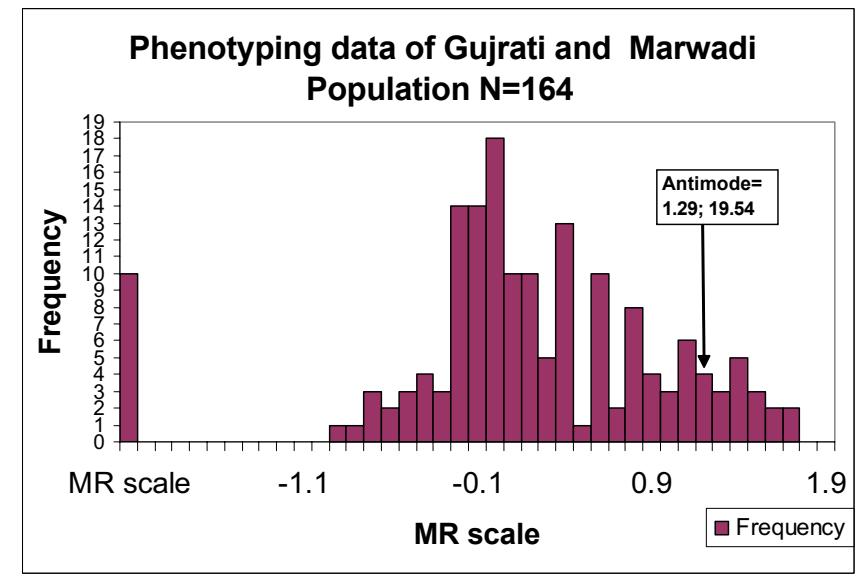

\section{Figure I}

Frequency distribution curve of the phenotyping data showing demarcation of extensive (EMs) and poor metabolizers (PMs) based on antimode calculations. Those with antimode greater than 19.54 classified as PMs.

females, 5(09.09\%) were PMs and 50(91.91\%) were EMs. Among the 109 males,12(11.00\%) were PMs and $97(89.00 \%)$ were EMs. In the individual subgroup of Gujratis, $4(8.88 \%)$ of the total 45 females and $10(12.98 \%)$ of the total 77 males were PMs, the \% of PMs in the subgroup as a whole being $11.47 \%$. In the Marwadi subgroup, $1(10 \%)$ of the total 10 females and $2(6.25 \%)$ of the total 32 were PMs, the \% of PMs in the subgroup as a whole being $7.14 \%$.

\section{Discussion and conclusion}

Most of the current literature related to pharmacogenetics of CYP2C19 has studied polymorphisms in Caucasians $[10,11]$, African-American [11] and Oriental populations [11], while far less is known about other ethnic groups. This is the first study from the country to establish the CYP2C19 phenotype frequencies in the Gujrati and Marwadi (Western Indian) population. Indian population comprises of more than 1 billion people. The population is divided into 4 major morphological types - Caucasoid, Mongoloid, Australoid and Negrito. The states of Mahar-

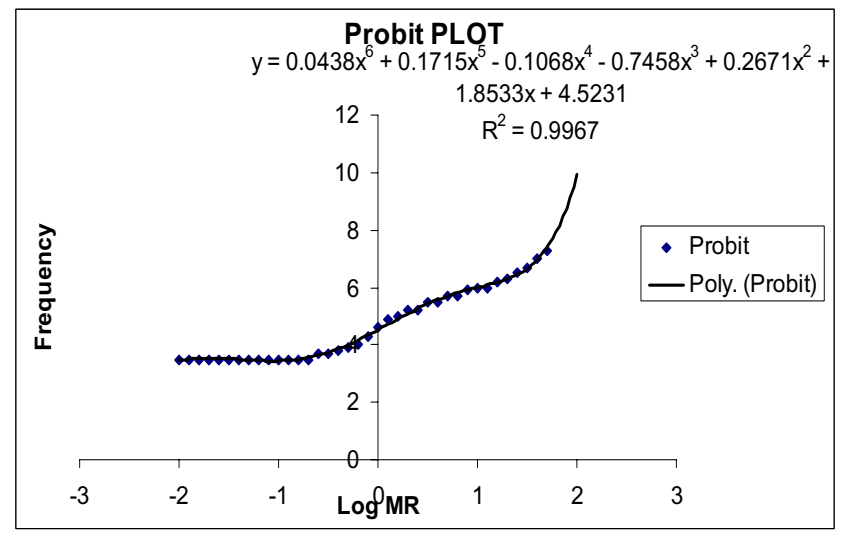

Figure 2

Probit plot obtained by curve fitting the log MR ratio data.

ashtra (Maharashtrians), Gujrat (Gujratis) and Rajasthan (Marwadis) belong to the Caucasoid morphological type [21]. All the subjects of the study are actually migrants to the city of Mumbai (Bombay). There were 122 Gujratis and 42 Marwadis. The states of Gujrat and Rajasthan share a common boundary and have socio cultural, and linguistic similarities and hence the total sample size was taken as 164 subjects.

It was seen that omeprazole metabolic ratio is a safe and convenient means for assessing the in-vivo activity of CYP2C19. This is in agreement with the use of omeprazole as a probe drug in other ethnic populations [22,23]. The prevalence of PMs in Gujratis and Marwadis was $10.36 \%$ by phenotyping, which is slightly lower than frequencies of South Indians (14\%) [18], North Indians (12\%) [17], Caucasians (3-5\%) [10], Africans (8\%) [12] and Orientals (12-23\%) [11]. There were differences in the distribution of PMs in Gujrati men (12.98\%PMs) and women (8.8\%PMs); as well as Marwadi men(6.25\%PMs) and women(10\%PMs), even though the overall incidence of PMs in the study group in both sexes was similar. The number of PMs was too small to do a meaningful statistical analysis. A total of 7/164 subjects were non vegetarians. Of these, 3 were Marwadis and 4 were Gujratis. None of the 7 were poor metabolizers and thus cannot explain

Table I: Data on PMs and EMs in Gujratis and Marwadis

\begin{tabular}{|c|c|c|c|c|}
\hline & & Gujratis $n=122$ & Marwadis $n=42$ & Total $N=164$ \\
\hline \multirow{3}{*}{ Males $n=109$} & $P M n=12$ & $10(12.98 \%)$ & $2(06.25 \%)$ & $12(11.00 \%)$ \\
\hline & $E M n=97$ & $67(87.02 \%)$ & $30(93.75 \%)$ & 97 (89\%) \\
\hline & total & 77 & 32 & 109 \\
\hline \multirow[t]{3}{*}{ Females $n=55$} & $P M n=5$ & $4(08.88 \%)$ & I (10.00\%) & $5(09.09 \%)$ \\
\hline & $E M n=50$ & $41(91.12 \%)$ & $9(90.00 \%)$ & 50 (91.91\%) \\
\hline & total & 45 & 10 & 55 \\
\hline
\end{tabular}


the PM status. A total of 10 subjects had a very low MR. It has been reported in literature that super rapid metabolizers exist and these set of patients are non responders to proton pump inhibitors. It has been hypothesized to be caused by variant of the wild type allele. It is possible that these 10 subjects could belong to this category. [24]

CYP2C19 metabolizes many clinically important drugs, notably proton-pump inhibitors, proguanil and benzodiazepines. The clinical implications of the CYP2C19 metabolism are many and varied, ranging from marked efficacy in the treatment of Helicobacter pylori infection with omeprazole in PMs to increased risk of failure of anti-malarial prophylaxis with proguanil in the same subgroup. This study was done as a part of a project to determine the polymorphisms of CYP2C19 by phenotyping as well as genotyping. The fact that $10.36 \%$ of our study population possesses the PM phenotype makes it essential to evaluate the phenotype-genotypes correlation in this population which can be done after the genotyping data is available. This is required to circumvent adverse drug reactions associated with increased accumulation of the parent drug and would also serve to decrease cost and duration of therapy, as a lower dose may suffice in the individuals who do not metabolize the drug extensively.

\section{Competing interests}

The author(s) declare that they have no competing interests.

\section{Authors' contributions}

TSP and SFN were the undergraduate students who executed the study. They recruited subjects, obtained informed consent, supervised drug administration and collected the blood samples. They also assisted in the statistical analysis. TSP wrote the first draft of the manuscript. SD carried out the entire statistical analysis and contributed to finalizing the methods and statistical section of the manuscript. VMS was responsible for the HPLC analysis. NJG and NAK conceived the study, wrote the protocol, submitted and obtained ethics committee approval, acted as overall project supervisors and made critical contributions to the manuscript at each stage and finalized the paper for submission.

\section{Acknowledgements}

We wish to thank all the study participants as well as the staff of the Department of Clinical Pharmacology for their assistance in conducting the study. We also thank Mr Abhijit Karwa who rendered valuable help in volunteer recruitment. We wish to thank Cipla Ltd for the supply of omeprazole powder and capsules. The authors are also grateful to Dr Kjell Anderson from Astra Zeneca, Sweden, for the donation of 5-hydroxy omeprazole pure powder and $\operatorname{Dr} C$ Adithan Professor - Director in Pharmacology at JIPMER, Pondicherry for training given in pharmacogenetics. This study was done as a short term studentship (STS) project by the second author under the Indian Council of Medical Research (ICMR) undergradu- ate student research scheme for the year 2006 and under the aegis of the ICMR centre for advanced research in Clinical Pharmacology. The authors are also grateful to the Department of Science and Technology, for funding the HPLC under their FIST scheme.

\section{References}

I. Meyer UA, Zanger UM: Molecular mechanisms of genetic polymorphisms of drug metabolism. Annu Rev Pharmacol Toxicol 1997, 37:269-96.

2. McLeod HL, Evans WE: Pharmacogenomics: unlocking the human genome for better drug therapy. Annu Rev Pharmacol Toxicol 200I, 4I:I0I-2I.

3. Weinshilboum R: Inheritance and drug response. N Engl J Med 2003, 348:529-537.

4. Evans WE, McLeod HL: Pharmacogenomics-drug disposition, drug targets, and side effects. N Engl J Med 2003, 348:538-549.

5. Evans WE, Johnson JA: Pharmacogenomics: the inherited basis for interindividual differences in drug response. Annu Rev Genomics Hum Genet 200I, 2:9-39.

6. Ingelman-Sundberg M, Oscarson M, Daly AK, Garte S, Nebert DW: Human cytochrome P450 (CYP) alleles a web page for the nomenclature of alleles. [http://www.imm.ki.se/CYPalleles/]. (accessed November 22, 2005)

7. Desta Z, Zhao X, Shin JG, Flockhart DA: Clinical significance of the cytochrome P450 2C19 genetic polymorphism. Clin Pharmacokinet 2002, 4I:9|3-58.

8. Kumana CR, Lauder IJ, Chan M, Ko W, Lin HJ: Differences in diazepam pharmacokinetics in Chinese and white Caucasians - relation to body lipid stores. Eur J Clin Pharmacol 1987, 32:2II-5.

9. Daly AK: Pharmacogenetics of the cytochromes P450. Curr Top Med Chem 2004, 4:1733-44.

10. Ibeanu GC, Blaisdell J, Ghanayem BI, Beyeler C, Benhamou S, Bouchardy C, Wilkinson GR, Dayer P, Daly AK, Goldstein JA: An additional defective allele, CYP2CI $9 * 5$, contributes to the $S$ mephenytoin poor metabolizer phenotype in Caucasians. Pharmacogenetics 1998, 8: I29-135.

II. Goldstein JA, Ishizaki T, Chiba K, de Morais SM, Bell D, Krahn PM, Evans DA: Frequencies of the defective CYP2C19 alleles responsible for the mephenytoin poor metabolizer phenotype in various Oriental, Caucasian, Saudi Arabian and American black populations. Pharmacogenetics 1997, 7:59-64.

12. Herrlin K, Massele AY, Rimoy G, Alm C, Rais M, Ericsson O, Bertilsson L, Gustafsson LL: Slow chloroguanide metabolism in Tanzanians compared with white subjects and Asian subjects confirms a decreased CYP2CI 9 activity in relation to genotype. Clin Pharmacol Ther 2000, 68: 189-98.

13. Chang M, Tybring G, Dahl M-L, Götharson E, Sagar M, Seensalu R, Bertilsson L: Interphenotype differences in disposition and effect on gastrin levels of omeprazole-suitability of omeprazole as a probe for CYP2C19. Br J Clin Pharmacol 1995, 39:5II-5I8.

14. Somogyi AA, Reinhard HA, Bochner F: Pharmacokinetic evaluation of proguanil: a probe phenotyping drug for the mephenytoin hydroxylase polymorphism. Br J Clin Pharmacol 1996, 41:175-179.

15. Furuta T, Ohashi K, Kamata T, Takashima M, Kosuge K, Kawasaki T, Hanai H, Kubota T, Ishizaki T, Kaneko E: Effect of genetic differences in omeprazole metabolism on cure rates for Helicobacter pylori infection and peptic ulcer. Ann Intern Med 1998, 1 29: 1027-30.

16. Tanigawara Y, Aoyama N, Kita T, Shirakawa K, Komada F, Okumura $\mathrm{K}:$ CYP2CI 9 genotype-related efficacy of omeprazole for the treatment of infection caused by Helicobacter pylori. Clin Pharmacol Ther 1999, 66:528-534.

17. Lamba JK, Dhiman RK, Kohli KK: CYP2C19 genetic mutations in North Indians. Clin Pharmacol Ther 2000, 68:328-35.

18. Rosemary J, Adithan C, Padmaja N, Shashindran CH, Gerard N, Krishnamoorthy R: The effect of the CYP2C19 genotype on the hydroxylation index of omeprazole in South Indians. Eur J Clin Pharmacol 2005, 61:19-23.

19. Ethical Guidelines for Biomedical Research in Human subjects of the Indian Council of Medical Research. 2000.

20. Kobayashi K, Chiba K, Sohn DR, Kato Y, Ishizaki T: Simultaneous determination of omeprazole and its metabolites in plasma 
and urine by reversed-phase high-performance liquid chromatography with an alkaline-resistant polymer-coated CI8 column. J Chromatogr 1992, 579:299-305.

21. Malhotra KC: Morphological composition of the people of India. J Hum Evol 1978, 7:45-63.

22. de Morais SM, Goldstein JA, Xie HG, Huang SL, Lu YQ, Xia H, Xiao ZS, Ile N, Zhou HH: Genetic analysis of the S-mephenytoin polymorphism in a Chinese population. Clin Pharmacol Ther 1995, 58:404-II.

23. Balian JD, Sukhova N, Harris JW, Hewett J, Pickle L, Goldstein JA, Woosley RL, Flockhart DA: The hydroxylation of omeprazole correlates with S-mephenytoin metabolism: a population study. Clin Pharmacol Ther 1995, 57:662-629.

24. Sim SCM, Aklillu E, Edwards RJ, Ahlberg S, Bertilsson L, Ingelman-Sundberg M: Identification of an CYP2CI 9 allele (CYP2CI9*ID) causing enhanced expression. Proceedings of The International Symposium On Microsomes And Drug Oxidations; 2004 Jul 4-9; Mainz, Germany. Mainz: The Symposium 2004.

\section{Pre-publication history}

The pre-publication history for this paper can be accessed here:

http://www.biomedcentral.com/1472-6904/6/8/prepub

Publish with Bio Med Central and every scientist can read your work free of charge

"BioMed Central will be the most significant development for disseminating the results of biomedical research in our lifetime."

Sir Paul Nurse, Cancer Research UK

Your research papers will be:

- available free of charge to the entire biomedical community

- peer reviewed and published immediately upon acceptance

- cited in PubMed and archived on PubMed Central

- yours - you keep the copyright

Submit your manuscript here:

http://www.biomedcentral.com/info/publishing_adv.asp 